\title{
2003 INDEX BY SUBJECT
}

A

\section{Aboriginal people}

An innovative sexual health medication order system for the Far West Area Health Service, 2003 14(6), 113-116

NSW Health Aboriginal Health Impact Statement: references and resources about Aboriginal people and Aboriginal Health, 2003 14(7), 147-148

aged care

An outbreak of Norwalk-like virus gastroenteritis in an agedcare residential hostel, 2003 14(6), 105-109

\section{air pollution}

Suspected pesticide poisoning: a back-of-the-envelope health risk assessment, 2003 14(8), 168-170

\section{anthrax}

Anthrax and other suspect powders: initial responses to an outbreak of hoaxes and scares, 2003 14(11-12), 218-221

Laboratory investigation of suspected bioterrorism incidents, NSW, October 2001 to February 2002, 2003 14(11-12), 221-223

\section{antibiotic resistance}

Factsheet: methicillin resistant Staphylococcus aureus, 2003 14(6), 123

\section{Area Health Services}

Release of the 2002 Area Health Service Reports, 2003 14(6), $119-121$

\section{Australia}

Immunisation coverage: Australia 2001, 2003 14(4-5), 94

Vaccine preventable diseases and vaccination coverage in Australia, 1999-2000, 2003 14(4-5), 94

\section{B}

\section{bioterrorism}

Laboratory investigation of suspected bioterrorism incidents, NSW, October 2001 to February 2002, 2003 14(11-12), $221-223$

boils

Factsheet: Boils and impetigo, 2003 14(1-2), 29

\section{breast cancer}

A consumer-initiated survey of women's experiences of breast cancer services in NSW, 2003 14(6), 117-119

\section{brucellosis}

Laboratory investigation of suspected bioterrorism incidents, NSW, October 2001 to February 2002, 2003 14(11-12), 221-223

\section{C}

cervical cancer

Halving deaths from cervical cancer, 2003 14(3), 55-56

\section{children see immunisation; infants}

\section{communicable diseases see infectious diseases}

community consultation

Community involvement and self-rated health status: findings from a cross-sectional survey in Central Sydney, 2003 14(11-12), 213-217

\section{conferences}

Celebrating the past; awakening the future: the NSW Public Health Forum highlights public health successes in NSW, 2003 14(3), 41-43

consumers

A consumer-initiated survey of women's experiences of breast cancer services in NSW, 2003 14(6), 117-119

\section{correctional centres}

Moving towards a statewide approach to court diversional services in NSW, 2003 14(11-12), 227-229

coxsackieviral diseases

Factsheet: Hand, foot and mouth disease, 2003 14(4-5), 95

cruise ships

The Sydney Olympics: a win for public health, 2003 14(3), $43-45$

D

\section{diet and nutrition}

Risk assessment for the consumption of fish with elevated selenium levels, 2003 14(8), 174-176

disasters

The Sydney Olympics: a win for public health, 2003 14(3), $43-45$

E

\section{enteroviral diseases}

Factsheet: Hand, foot and mouth disease, 2003 14(4-5), 95

environmental health

The Sydney Olympics: a win for public health, 2003 14(3), 43-45

epidemiology

A pertussis epidemic in NSW: how epidemiology reflects vaccination policy, 2003 14(4-5), 77-81

Australia's national serosurveillance program, 2003 14(4-5), 90-93

Differences in the epidemiology of invasive pneumococcal disease, metropolitan NSW, 1997-2001, 2003 14(4-5), $85-89$

Do variations in pertussis notifications reflect incidence or surveillance practices? A comparison of infant notification rates and hospitalisation data in NSW, 2003 14(4-5), 81-84

Vaccine preventable diseases and vaccination coverage in Australia, 1999-2000, 2003 14(4-5), 94

explosives

Firework injuries in New South Wales, 1992-93 to 2001-02, 2003 14(6), 110-113

$\mathbf{F}$

\section{fact sheets}

Factsheet: Boils and impetigo, 2003 14(1-2), 29

Factsheet: Hand, foot and mouth disease, 2003 14(4-5), 95

Factsheet: Influenza, 2003 14(8), 181

Factsheet: Meningococcal disease, 2003 14(7), 150

Factsheet: Methicillin resistant Staphylococcus aureus, 2003 14(6), 123

Factsheet: Severe acute respiratory syndrome (SARS), 2003 14(3), 62

Factsheet: Viral gastroenteritis, 2003 14(9-10), 206-207

firearms

The decline in gun deaths, 2003 14(3), 48-50

fireworks

Firework injuries in New South Wales, 1992-93 to 2001-02, 2003 14(6), 110-113

foodborne diseases see also gastroenteritis

The Sydney Olympics: a win for public health, 2003 14(3), $43-45$

G

\section{gastroenteritis}

An outbreak of Norwalk-like virus gastroenteritis in an agedcare residential hostel, 2003 14(6), 105-109 
Factsheet: Viral gastroenteritis, 2003 14(9-10), 206-207

H

hand, foot and mouth disease

Factsheet: Hand, foot and mouth disease, 2003 14(4-5), 95

health services

Release of the 2002 Area Health Service Reports, 2003 14(6), 119-121

\section{health status}

Community involvement and self-rated health status: findings from a cross-sectional survey in Central Sydney, 200314 (11-12), 213-217

hepatitis

Hepatitis B immunisation in children aged 10-13 in New South Wales, 2001, 2003 14(1-2), 17-20

historical events

Building the infrastructure for public health, 2003 14(3), 50-51

\section{HIV/AIDS}

Containing HIV in NSW: a world class success, 2003 14(3), 57-59

hoaxes

Anthrax and other suspect powders: initial responses to an outbreak of hoaxes and scares, 2003 14(11-12), 218-221

\section{iatrogenic disorders}

Immunisation adverse events clinics, 2003 14(1-2), 25-27

Monitoring adverse events following immunisation, 2003 14(1-2), 21-24

I

immunisation see also specific diseases eg, hepatitis; vaccine storage

A pertussis epidemic in NSW: how epidemiology reflects vaccination policy, 2003 14(4-5), 77-81

Australia's national serosurveillance program, 2003 14(4-5), 90-93

Hepatitis B immunisation in children aged 10-13 in New South Wales, 2001, 2003 14(1-2), 17-20

Immunisation adverse events clinics, 2003 14(1-2), 25-27

Immunisation coverage: Australia 2001, 2003 14(4-5), 94

Immunisation: a public health success, 2003 14(1-2), 1-5

Mapping immunisation coverage and conscientious objectors to immunisation in NSW, 2003 14(1-2), 8-12

Measles control in NSW divisions of general practice, 2003 14(1-2), 13-17

Monitoring adverse events following immunisation, 2003 14(12), 21-24

Tears often shed, 2003 14(1-2), 5-8

Vaccine preventable diseases and vaccination coverage in Australia, 1999-2000, 2003 14(4-5), 94

impetigo

Factsheet: Boils and impetigo, 2003 14(1-2), 29

infants (babies)

Release of New South Wales Mothers and Babies 2001, 2003 14(6), 122

infectious diseases see also notifications; names of specific diseases and organisms

Communicable diseases report, NSW: January-February 2003, 2003 14(1-2), 30-38

Communicable diseases report, NSW: March 2003, 2003 14(3), 63

Communicable diseases report, NSW: April-May 2003, 2003 14(4-5), 96-103

Communicable diseases report, NSW: June 2003, 2003 14(6), 124-129

Communicable diseases report, NSW, for May 2003, 2003 14(7), 151-158
Communicable diseases report, NSW, for June 2003, 2003 14(8), 182-185

Communicable diseases report, NSW, for July 2003, 2003 14(9-10), 207-208

Communicable diseases report, NSW, for August and September 2003, 2003 14(11-12), 232-238

Priorities for communicable disease control in New South Wales, 2003, 2003 14(9-10), 200-205

Year in review: communicable disease surveillance, 2002, 2003 14(9-10), 189-199

\section{influenza}

Factsheet: Influenza, 2003 14(8), 181

injuries and accidents

Firework injuries in New South Wales, 1992-93 to 2001-02, 2003 14(6), 110-113

L

laboratories

Laboratory investigation of suspected bioterrorism incidents, NSW, October 2001 to February 2002, 2003 14(11-12), 221-223

land contamination

But you don't have to live here! Risk assessment and contaminated sites: a case study, 2003 14(8), 171-173

legal issues

Moving towards a statewide approach to court diversional services in NSW, 2003 14(11-12), 227-229

leptospirosis

Factsheet: Leptospirosis, 2003 14(11-12), 230-231

M

measles

Measles control in NSW divisions of general practice, 2003 14(1-2), 13-17

medication

An innovative sexual health medication order system for the Far West Area Health Service, 2003 14(6), 113-116

meningococcal disease

Factsheet: Meningococcal disease, 2003 14(7), 150

mental illness

Moving towards a statewide approach to court diversional services in NSW, 2003 14(11-12), 227-229

methicillin

Factsheet: Methicillin resistant Staphylococcus aureus, 2003 14(6), 123

mortality

Halving deaths from cervical cancer, 2003 14(3), 55-56

Has pertussis increased in NSW over the past decade? An evaluation using hospitalisation and mortality data versus notifications 1988-2002, 2003 14(4-5), 71-76

The decline in gun deaths, 2003 14(3), 48-50

mothers

Release of New South Wales Mothers and Babies 2001, 2003 14(6), 122

N

New South Wales

Mapping immunisation coverage and conscientious objectors to immunisation in NSW, 2003 14(1-2), 8-12

Norwalk-like viruses

An outbreak of Norwalk-like virus gastroenteritis in an agedcare residential hostel, 2003 14(6), 105-109

notifications

Do variations in pertussis notifications reflect incidence or surveillance practices? A comparison of infant notification rates and hospitalisation data in NSW, 2003 14(4-5), 81-84 
Has pertussis increased in NSW over the past decade? An evaluation using hospitalisation and mortality data versus notifications 1988-2002, 2003 14(4-5), 71-76

Year in review: communicable disease surveillance, 2002, 2003 14(9-10), 189-199

nutrition see diet and nutrition

0

Olympic and Paralympic Games (Sydney 2000)

The Sydney Olympics: a win for public health, 2003 14(3), 43-45

P

pertussis (whooping cough)

A pertussis epidemic in NSW: how epidemiology reflects vaccination policy, 2003 14(4-5), 77-81

Do variations in pertussis notifications reflect incidence or surveillance practices? A comparison of infant notification rates and hospitalisation data in NSW, 2003 14(4-5), 81-84

Has pertussis increased in NSW over the past decade? An evaluation using hospitalisation and mortality data versus notifications 1988-2002, 2003 14(4-5), 71-76

Lessons from surveillance: solving the pertussis puzzle, 2003 14(4-5), 69-71

\section{pesticides}

Suspected pesticide poisoning: a back-of-the-envelope health risk assessment, 2003 14(8), 168-170

\section{pneumococcal infection}

Differences in the epidemiology of invasive pneumococcal disease, metropolitan NSW, 1997-2001, 2003 14(4-5), 85-89

\section{policy development}

A pertussis epidemic in NSW: how epidemiology reflects vaccination policy, 2003 14(4-5), 77-81

Priorities for communicable disease control in New South Wales, 2003, 2003 14(9-10), 200-205

pollution see also air pollution; water pollution

But you don't have to live here! Risk assessment and contaminated sites: a case study, 2003 14(8), 171-173

\section{psittacosis}

Communicable diseases report, NSW: March 2003, 2003 14(3), 63

public health

Building the infrastructure for public health, 2003 14(3), 50-51

Celebrating the past; awakening the future: the NSW Public Health Forum highlights public health successes in NSW, 2003 14(3), 41-43

Continuous NSW Health Survey: quarterly report on health status, health behaviours, and risk factors, 2003 14(7), $144-146$

\section{$\mathbf{R}$}

\section{resource allocation}

Priorities for communicable disease control in New South Wales, 2003, 2003 14(9-10), 200-205

\section{risk factors}

But you don't have to live here! Risk assessment and contaminated sites: a case study, 2003 14(8), 171-173

Continuous NSW Health Survey: quarterly report on health status, health behaviours, and risk factors, 2003 14(7), $144-146$

Quantitative health risk assessment, 2003 14(8), 161-165

Release of the 2002 Area Health Service Reports, 2003 14(6), 119-121

Risk assessment for the consumption of fish with elevated selenium levels, 2003 14(8), 174-176
Suspected pesticide poisoning: a back-of-the-envelope health risk assessment, 2003 14(8), 168-170

What does it mean when the risk assessment says $4.73 \times 10$ 5?, 2003 14(8), 166-167

\section{Ross River fever}

Ross River virus in western Sydney, 2003 14(11-12), 224-226

rural health

An innovative sexual health medication order system for the Far West Area Health Service, 2003 14(6), 113-116

S

selenium

Risk assessment for the consumption of fish with elevated selenium levels, 2003 14(8), 174-176

severe acute respiratory syndrome (SARS)

Factsheet: Severe acute respiratory syndrome (SARS), 2003 14(3), 62

sexuality

Sex in Australia: the Australian study of health and relationships, 2003 14(7), 143-144

sexually transmitted diseases see also names of specific

diseases e.g., syphilis

An innovative sexual health medication order system for the Far West Area Health Service, 2003 14(6), 113-116

The Australian Study of Health and Relationships: Results for Central Sydney, Inner-eastern Sydney, and New South Wales, 2003 14(7), 133-143

smoking

Reducing tobacco consumption, 2003 14(3), 46-48

socioeconomic factors

Assessing disadvantage and health: the Mount Druitt pilot study, 2003 14(7), 149

Sex in Australia: the Australian study of health and relationships, 2003 14(7), 143-144

The Australian Study of Health and Relationships: Results for Central Sydney, Inner-eastern Sydney, and New South Wales, 2003 14(7), 133-143

Staphylococcus aureus

Factsheet: Methicillin resistant Staphylococcus aureus, 2003 14(6), 123

surveys

A consumer-initiated survey of women's experiences of breast cancer services in NSW, 2003 14(6), 117-119

Assessing disadvantage and health: the Mount Druitt pilot study, 2003 14(7), 149

Australia's national serosurveillance program, 2003 14(4-5), 90-93

Community involvement and self-rated health status: findings from a cross-sectional survey in Central Sydney, 2003 14(1112), 213-217

Continuous NSW Health Survey: quarterly report on health status, health behaviours, and risk factors, 2003 14(7), 144146

Differences in the epidemiology of invasive pneumococcal disease, metropolitan NSW, 1997-2001, 2003 14(4-5), 85-89

Do variations in pertussis notifications reflect incidence or surveillance practices? A comparison of infant notification rates and hospitalisation data in NSW, 2003 14(4-5), 81-84

Has pertussis increased in NSW over the past decade? An evaluation using hospitalisation and mortality data versus notifications 1988-2002, 2003 14(4-5), 71-76

Lessons from surveillance: solving the pertussis puzzle, 2003 14(4-5), 69-71

Ross River virus in western Sydney, 2003 14(11-12), 224-226 
Sex in Australia: the Australian study of health and relationships, 2003 14(7), 143-144

The Australian Study of Health and Relationships: Results for Central Sydney, Inner-eastern Sydney, and New South Wales, 2003 14(7), 133-143

swimming pools

Taking the plunge: recreational water quality guidelines, 2003 14(8), 177-180

$\mathbf{T}$

tobacco sales

Reducing tobacco consumption, 2003 14(3), 46-48

\section{U}

\section{urban populations}

Assessing disadvantage and health: the Mount Druitt pilot study, 2003 14(7), 149

Community involvement and self-rated health status: findings from a cross-sectional survey in Central Sydney, 200314 (11-12), 213-217
Differences in the epidemiology of invasive pneumococcal disease, metropolitan NSW, 1997-2001, 2003 14(4-5), 85-89

Ross River virus in western Sydney, 2003 14(11-12), 224-226

The Australian Study of Health and Relationships: Results for Central Sydney, Inner-eastern Sydney, and New South Wales, 2003 14(7), 133-143

W

water pollution

Risk assessment for the consumption of fish with elevated selenium levels, 2003 14(8), 174-176

Taking the plunge: recreational water quality guidelines, 2003 14(8), 177-180

women's health

A consumer-initiated survey of women's experiences of breast cancer services in NSW, 2003 14(6), 117-119

\section{INDEX BY AUTHOR}

A

\section{Allchin L}

200314 (11-12), 224

\section{B}

\section{Balding B}

200314 (3), 52

Billett J

200314 (6), 117

Bird P

200314 (8), 174

Bourne C

200314 (6), 113

Brotherton J

200314 (4-5), 77

Burgess M

$200314(1-2), 1$

200314 (1-2), 5

200314 (1-2), 13

Burke H

200314 (3), 52

C

Campbell B 200314 (6), 105

Campbell-Lloyd S 200314 (1-2), 21

Champion R 200314 (3), 59

Chapman $\mathbf{S}$

200314 (3), 46

200314 (3), 48

\author{
Corbett S \\ 200314 (8), 161 \\ Correll PK \\ 200314 (1-2), 17 \\ Cowie C \\ 200314 (8), 177 \\ Crossing S \\ 200314 (6), 117 \\ D \\ Dalton C \\ 200314 (8), 174 \\ de Visser $\mathbf{R}$ \\ 200314 (7), 133 \\ Delpech V \\ 200314 (11-12), 218 \\ E \\ Eyeson-Annan M \\ 200314 (1-2), 17 \\ 200314 (6), 119 \\ 200314 (7), 144 \\ F \\ Frommer M \\ 200314 (7), 147 \\ G \\ Gay N \\ 200314 (1-2), 13 \\ Gethin A \\ 200314 (7), 149 \\ Gidding $\mathbf{H}$ \\ 200314 (4-5), 90
}

Gilbert L

200314 (11-12), 221

Gilmour R

200314 (4-5), 85

Gray J

200314 (3), 59

Greenberg D

200314 (11-12), 227

Grulich A

200314 (7), 133

Gupta L

200314 (6), 105

H

Harvey L

200314 (6), 119

200314 (7), 144

Hayen A

200314 (1-2), 17

200314 (7), 144

Hickey C

200314 (8), 177

Hort K

200314 (11-12), 224

Hull B

200314 (1-2), 8

200314 (1-2), 13

J

James G

200314 (11-12), 221

Jorm LR

200314 (3), 43

200314 (6), 110 


\section{K}

Knight V

200314 (6), 113

L

Langley A

200314 (8), 166

Lawrence G

200314 (1-2), 21

Leask A

200314 (11-12), 218

Leeder $\mathrm{S}$

200314 (3), 41

Liu B

200314 (6), 105

Lyle D

200314 (3), 52

\section{M}

MacIntyre CR 200314 (1-2), 13

Madden L

200314 (3), 50

Maywood P

200314 (6), 105

McAnulty J

200314 (4-5), 77

200314 (9-10), 200

200314 (11-12), 218

\section{McIntyre $\mathbf{P}$}

200314 (1-2), 8

200314 (4-5), 69

200314 (4-5), 71

200314 (4-5), 81

200314 (4-5), 85
Menzies R

200314 (4-5), 71

Ming Wen L

200314 (11-12), 213

Morey S

200314 (3), 50

\section{$\mathbf{N}$}

Nielsen B

200314 (11-12), 227

0

Ooi C

200314 (6), 113

P

Penny $R$ 200314 (3), 57

Ptolemy H 200314 (11-12), 224

R

Richards G 200314 (8), 168

Richters J

200314 (7), 133

Rissel C

200314 (7), 133

200314 (7), 143

200314 (11-12), 213

Rixon G

200314 (1-2), 21

Rutherford A

200314 (8), 171
S

Sainsbury $\mathbf{P}$ 200314 (11-12), 213

Smith A

200314 (7), 133

Stewart K

200314 (3), 57

200314 (9-10), 200

T

Taylor L

200314 (6), 122

Taylor R

200314 (3), 55

Todd A

200314 (7), 147

Torvaldsen S

200314 (4-5), 81

Truman G 200314 (11-12), 224

$\mathrm{v}$

Visotina $\mathbf{M}$ 200314 (3), 43

Voukelatos A 200314 (11-12), 213

W

Wang $\mathbf{H}$ 200314 (4-5), 71

Watson M 200314 (4-5), 85

Wood N

200314 (1-2), 25

Yuen M

200314 (11-12), 221 